\title{
The Benefits and Constraints of Temporary Sourcing Diversification in Supply Chain Disruption and Recovery
}

\author{
Daniel E. Whitneya, Jianxi Luo ${ }^{\mathrm{b}}$, Daniel A. Hellerc \\ a Engineering Systems Division, Massachusetts Institute of Technology \\ 77 Massachusetts Ave, E40-243, Cambridge, MA 02139, USA \\ b Engineering Product Development Pillar, Singapore University of Technology and Design \\ 20 Dover Drive, Singapore 138682, Singapore \\ c College of Business Administration,Yokohama National University \\ 79-1 Tokiwadai, Hodogaya-ku, Yokohama, 240-8501, Japan
}

\begin{abstract}
Sourcing diversification is the preferred hedge to supply chain disruption risks, but many companies insist on single-sourcing for long-term strategic benefits. For rare-but-catastrophic disruptions of fortified supply chains, temporary sourcing diversification has been seen as a desirable response strategy. However, little is known about the conditions to temporary sourcing diversification and the situations where it is applicable. Our fieldwork and comparison of two disaster recoveries at Aisin Seiki and Riken Corporation shows that while temporary sourcing diversification worked in the Aisin Seiki case, it was impossible at Riken due to the high degree of specificity required in the design and manufacturing methods of the disrupted product item, suggesting product and process specificity limit recovery alternatives. Unawareness of such constraints to temporary sourcing diversification may result in over-optimism regarding its feasibility and insufficient disaster preparedness. In addition, the case of Riken's recovery from an earthquake in 2007 is systematically documented in this paper for the first time.
\end{abstract}

Keywords: Supply chain disruption; disaster; risk management; temporary diversification; single-sourcing; product specificity; asset specificity; case studies

Publication: Journal of Purchasing \& Supply Management 20 (2014) 238-250 


\section{Introduction}

Recently, purchasing and supply management scholars have recognized supply disruption risk management as an important area of research (Schoenherr et al, 2012), especially seeing the increasing number of supply chain disruptions resulting from natural and other disasters (Kleindorfer and Van Wassenhove, 2004) and their huge impacts on firm and sector performances (Altay and Ramirez, 2010; Simchi-Levi et al, 2014). For instance, the 9.0magnitude quake and subsequent tsunami in March 2011 in Eastern Japan damaged or destroyed many factories and disrupted the world's electronics and automotive supply chains for a significant period of time. A single firm, Renesas Electronics, lost \$156 million as a result of damage to its Naka facility, which was designed to withstand an 8.0-magnitude earthquake, and it took three months to put the Naka facility back in operation (Courtland, 2011). The companies relying on their sole suppliers in Eastern Japan had to halt their production for months. In 2012, the hard disk drive industry was severely disrupted by the hundred-year floods in Thailand. Such risks induced by the rare-but-catastrophic disasters are often more severe than the operational risks of supplier unreliability affecting quality and delivery (Speier et al, 2011).

Yet in spite of the increasing disruption risks due to rare but devastating disasters (Simchi-Levi et al, 2014) and a supply diversification strategy being typically advisable to mitigate the risk (Wang, 2006; Wang and Tomlin, 2010), many companies still insist on concentrated supply of certain components and parts, or as we call it below, fortification--i.e. the use of few suppliers and reliance on vigorous recovery actions. They do so for the value of long-term learning abetted by repeated and deepened relationships, and a deliberate tradeoff of these long-term benefits against some obvious short-term risks (Braunscheidel and Suresh, 2009; Chopra and Sodhi, 2014; Nakamoto, 2007; Sheffi, 2005). Companies that resolve the tension between diversification and fortification by favoring the latter receive considerable criticism from the lay press when a disaster strikes (Allbusiness, 2007; Chozik, 2007a; Reitman, 1997a).

When a crisis occurs, blackout time and economic loss due to disruption can be limited through effective recovery actions (Sheffi, 2005; Tomlin, 2006; Tomlin and Wang, 2010). Some of these recoveries using temporary sourcing diversification, i.e. temporarily using alternate suppliers, 
become famous, as in the case of the fire in 1997 at Toyota's brake valve supplier Aisin Seiki (Nishiguchi and Beaudet, 1998; Reitman, 1997b; Treece, 1997), where Aisin Seiki temporarily procured brake valve machining from a variety of volunteer suppliers before Aisin Seiki fully recovered from that fire. This story has gained somewhat mythic status in supply chain risk management literature. It makes one believe that the availability of temporary sourcing diversification makes Just-In-Time (low inventories, rapid response at low cost, etc.) and single source supply chains resilient in an event of disruption, so as to limit losses (Sheffi, 2005). Yet, many recoveries from severe disasters do not involve numerous suppliers rising up to produce the item lost in the disaster, and temporary sourcing diversification may not be a viable option in some situations. Our understanding of the enablers and constraints of temporary sourcing diversification versus concentrated recovery efforts in response to the disruption of singlesourcing supply chains is still limited.

This paper aims to address this specific gap by comparing a pair of cases with the same singlesourcing mode in day-to-day supply chain operations, to reveal how the differences in technicaleconomic factors, notably product and process specificity, conditioned different post-disaster response modes. Specifically, the Aisin Seiki fire case is compared to another less well-known but more recent recovery case after an earthquake that disrupted production of piston rings at Riken Corporation in Niigata Japan in 2007. Both cases similarly involve fortification in day-today supply chain operations: single or nearly single-source arrangements, low inventories, deep supplier relations, and severe disruption. However, after the disruption at Riken, no upwelling of alternate supplier support to make piston rings emerged. The case of Riken's recovery in 2007 is systematically documented in this paper for the first time.

Based on the on-site interviews and observations during visits to Aisin-Seiki and Riken in Japan, augmented with additional data from public sources, we found that temporary sourcing diversification was and remains impossible at Riken because of the high degree to which piston rings are specifically designed and manufactured for their respective engines, an instance of asset specificity (Williamson, 1981). Such high asset specificity required in the disrupted product item and related development and manufacturing methods of the item makes it difficult to obtain or learn capabilities quickly when needed, thus constraining the availability of temporary alternate 
suppliers when the disruption took place. For components and parts in complex products, a Riken-like response is more likely than the Aisin-Seiki response as increased competition on quality and cost drives components and parts to be designed more specifically and produced using specific assets.

This paper contributes to a growing body of literature on supply disruption risk management (Altay and Ramirez, 2010; Bode et al, 2011; Ellis et al, 2011; Giannakis and Louis, 2011; Hoffmann et al, 2013; Simchi-Levi et al, 2014), by specifying how product and process specificity may condition disruption recovery modes from rare-but-catastrophic supply disruptions, and in particular the feasible conditions for the highly touted temporary diversification mode for the recovery of single-sourcing supply chains (Nishiguchi and Beaudet, 1998; Sheffi, 2005; Watts, 2003). Although the supply management literature has hinted at the necessity to consider product attributes in disruption risk management (Ellis et al, 2011), in depth and detailed correlations have not been made prior to the present study. Our study adds a specific insight, namely the impact of product and process attributes on supply disruption recoveries, to recently-proposed broad frameworks in the literature that aim to either understand or manage supply chain risks (Braunscheidel and Suresh, 2009; Ellis et al., 2011; Kleindorfer and Saad, 2005; Narasimhan and Talluri, 2009; Simchi-Levi et al, 2014).

Our work also contributes to real business practices. For supply chain managers, ignorance of such technical conditions that influence the availability of temporary sourcing diversification may result in over-optimism and insufficient preparedness. Insights from this paper may also guide insurance firms to assess more systematically the risk and expected loss due to potential supply chain disruptions of their clients, by helping them estimate accurately the speed with which disruptions in supply chains can likely be recovered. Insurance firms are interested in fast recoveries of disruption incidents in order to reduce the claims related to the insurance products and services they offer to protect against extended business interruption risk.

The rest of this paper is organized as follows. We first review the relevant literature in Section 2. Section 3 explains our research methodology and data collection. Section 4 covers the wellknown Aisin Seiki fire case and details the new case on the Riken disruption. Section 5 is a 
cross-case comparison, and it is followed by a broader discussion in Section 6. Section 7 concludes with discussing limitations and future research opportunities.

\section{Literature review}

\subsection{Supply chain disruption risk management}

Supply chain risk management is identified as one of the five most intriguing areas of opportunities in purchasing and supply management research, by a panel of leading scholars in this academic field (Schoenherr et al, 2012). According to Kleindorfer and Saad (2005), supply chain risks fall into two broad categories: operational risk from supplier unreliability and the coordination between supply and demand, i.e. quality and delivery issues, and risk from disruption of normal activities due to strikes, terrorist attacks, fires, natural and other disasters. This paper is mainly concerned with disruption risk.

Considering the complex and multidimensional nature of supply disruption risks, a few general frameworks have been proposed to understand and manage supply disruption risks (Ellis et al, 2011; Narasimhan and Talluri, 2009; Simchi-Levi et al, 2014). For example, Braunscheidel and Suresh (2009) suggested that market and learning orientations affect firm practices including internal integration, external integration and external flexibility, so are drivers for augmenting supply chain agility as a risk management initiative. Ellis et al (2011) surveyed extensive literatures to identify sets of environmental, organizational and individual factors that affect the firms' perceptions of supply disruption risks and the social and psychological factors that drive risk mitigation decisions and actions. The empirical findings of Zsidisin and Wagner (2010) indicate that "grass-roots" supply managers' perceptions of supply-side risks drive their attitudes and ex-ante or ex-post approaches to risk management, suggesting senior management should implement systematic tools to capture the knowledge of supply management professionals.

Disruption risk management is often divided into risk mitigation, i.e. proactive preparedness before the disruption, and responsiveness, i.e. contingency actions once the disruption has occurred (Hoffmann et al, 2013; Knemeyer et al, 2009; Tomlin, 2006). Typical risk mitigation 
strategies include carrying buffer inventories (Bode et al, 2011; Song and Zipkin, 1996; Tomlin, 2006), diversifying suppliers (Dada et al, 2007; Tomlin and Wang, 2005; Tomlin, 2009) and strengthening customer-supplier relations (Bode et al, 2011; Liker and Choi, 2004; Wagner and Silveira-Camargos, 2012). Typical response strategies include using alternate or standby suppliers (Chopra et al., 2007; Tomlin, 2006; Tomlin, 2009) and demand shift/management (Tomlin, 2009). Each of these strategies may be driven by the cognitive capabilities or specific motivations of the firms (Ellis et al, 2011), and has strengths and limitations, for which Tomlin and Wang (2010) provide a comprehensive review.

In some circumstances, combining several of the above strategies can provide significant value. For example, Wang et al (2010) suggest a combined strategy of strengthening the supplier and dual sourcing, while Tomlin (2006) suggests the mix of carrying inventory and using backup suppliers, under certain conditions. In addition, a complete supply chain risk management program should also include risk monitoring, identification and assessment in addition to mitigation and responses (Hoffmann et al, 2013; Kleindorfer and Saad, 2005). We must note that all these involve costs, whether for finding out what and how much the risk is, mitigating it, or setting up responses.

In fact, we cannot separate risk mitigation and response as they are intertwined. For instance, better preparation before the disruption leads to a better response once the disruption occurs. Furthermore, the risk mitigators, such as inventory, sourcing diversification and manufacturersupplier relationship, are also the keys of the day-to-day supply chain operations, which affect overall firm benefits such as efficiency and learning. However, the typical literature on supply chain risk management has paid little attention to long-term benefits, which motivate firms’ overall operations strategy, when discussing disruption risk mitigation. In the following, we review the benefits and costs of a few supply chain strategies, which also affect disruption risks.

\subsection{Supply chain strategy considering risk management}

Concerning the risk of disruption, firms may prefer to hold excess buffering inventory (Bode et al, 2011) or source from multiple alternate suppliers (Tomlin and Wang, 2010), depending on the 
level of perceived risks (Hoffmann et al, 2013; Simchi-Levi et al, 2014), in their normal supply chain operations. Such strategies aim to limit the loss at disruption, but have pitfalls and incur systemic costs from a long-term perspective (Chopra and Sodhi, 2014).

First, maintaining a high inventory in anticipation of a catastrophic event and/or disruption may reduce blackout periods (Tomlin and Wang, 2010). However, during regular operations, the high inventory may reduce working capital, cost efficiency and obscure operational problems (Chopra and Sodhi, 2014). It is especially unfavorable if disruptions are infrequent (Tomlin, 2006). Second, the risk mitigation literature often prefers diversification (don't put all your eggs in one basket) over concentration or fortification (put all your eggs in one basket and watch it carefully). Diversification reduces the risk of losing all resources in a disaster, and limits the loss from not having the resources for the blackout time (Tomlin and Wang, 2010). Diversification also offers opportunities to learn from alternate sources, plus enhancement of competition due to greater ease of switching. However, diversification incurs costs from added operational and organizational complexity, limits the depth of mutual trust and relationship with individual suppliers, and loses some value available from concentration, such as scale economies (Chopra and Sodhi, 2014; Sheffi, 2005).

The decision to fortify rather than diversify induces higher risk of losing the whole resource if a disaster strikes. Additional risks include resource dependence and holdup (Bode et al, 2011; Fine and Whitney, 1999; Williamson, 1981). The potential benefits of fortification include alignment of product design choices with manufacturing methods and operational strategy, plus opportunities for mutual learning about these alignments (Whitney, 1993) and conventional advantages such as scale economies. In particular, fortification becomes crucial when the procured part is highly interdependent with other parts of the final product, because that demands coordination in design and manufacturing across assembler and supplier, and requires both parties to invest in skills, assets and resources that are valuable only in the context of their specific relationship (Asanuma, 1998; Fujimoto, 2007; Luo et al., 2012; Sako, 1992;), in order to deliver a competitive level of quality, price and service (MacDuffie, 2008; Wang et al, 2010). In contrast, diversification is relatively easier to apply to parts that are modular (Baldwin and Clark, 
2000) and that can be made using general capabilities readily available from alternate sources (Ellis et al, 2011).

Therefore, from a mitigation perspective, "lean” or JIT supply chains bear a high risk of disruption in the event of disaster due to the deliberate choices of low inventory and fortification made for long-term operational benefits. The lean production principles (Womack et al, 1990) emphasize cost minimization (keeping inventory low), problem solving, long-term relationships, and collaborative learning and capability building, all of which fortification fosters. In the Japanese automotive industry (the context of our two cases for comparison), Toyota and other manufacturers generally hold the belief that the benefits of minimal inventory and fortification (single supplier for specialized automotive components/parts) far outweigh the risks of supply chain disruptions and associated losses (Fujimoto, 2001; 2007; Hopp and Spearman, 2004; MacDuffie, 1995; Nakamoto, 2007; Sheffi, 2005). Thus, despite repeated criticism from the lay press every time a disaster strikes and disrupts the lean supply chain, these companies consistently stick to such strategies (Allbusiness, 2007; Chozik, 2007a,b; Nakamoto, 2007; Reitman, 1997a).

Actually, fortification and low inventory are not necessarily wholly negative for risk management as they can offer benefits for response effectiveness. Fortification, through working closely with single partner for a long time, can explore synergies and strengthen relationships, which are beneficial for effective cooperation, coordination and collaboration across the customer and supplier firms in recovery efforts (Kleindorfer and Saad, 2005). In addition, tight inventories quickly reveal problems in the supply chain after they occur, allowing them to be addressed promptly (Nakamoto, 2007).

\subsection{Temporary sourcing diversification and limits}

Blackout time and economic loss due to disruption can be trimmed if responses are effective. The literature on contingency actions has paid increasing attention to temporary sourcing diversification, i.e. temporarily using alternate suppliers (Sheffi, 2005; Tomlin and Wang, 2010). It is also called "contingent rerouting” (Tomlin, 2006) or "backup supply" (Tomlin and Wang, 
2010) in the literature. Temporary sourcing diversification is increasingly favored over mitigation strategies as disruptions become less frequent but longer (Tomlin, 2006). Nonetheless, most of these modeling-based studies only considered one single alternative source that temporarily steps in during the disruption and assumes that this alternate was identified, contracted in advance of any specific disruption, and has the necessary capacity on standby reserve. In contrast, the empirical studies on the recovery of Aisin Seiki from a fire in 1997 show that the sourcing of P-valves was temporarily diversified to a huge number of impromptu suppliers before Aisin Seiki fully recovered (Nishiguchi and Beaudet, 1998; Sheffi, 2005; Reitman, 1997b).

Scholars have considered various enablers of such a wide range of temporary diversification in disruption recovery, including supply chain agility (Braunscheidel and Suresh, 2009), selforganization and social networking (Watts, 2003), knowledge emergence (Kakihara and Sørensen, 2002), collaborative spirit, trust and capability sharing (Nishiguchi and Beaudet, 1998; Sheffi, 2005). In particular, Nishiguchi and Beaudet’s (1998) seminal study on Aisin Seiki recovery argued that the Japanese "institutionalized mechanisms," such as supplier associations and Keiretsu, foster trust building and capability sharing among firms, which make possible such a broad range of suppliers for temporary sourcing diversification.

However, our analysis below of a more recent disruption recovery (at Riken Corporation) in the same culture context (Japan), industry context (automotive parts), and operational context (JIT, low inventory and single sourcing), show that Riken and Toyota's contingency actions did not involve temporary alternate suppliers. Clearly temporary sourcing diversification is not the only response mode, and knowledge-sharing and trust might not be the only influences to disaster responsive capabilities. Tomlin and Wang (2010) have implied that temporary sourcing diversification is only available when there is an additional provider capable of performing the disrupted activity, and it must also have additional capacity, i.e. volume flexibility (Tomlin, 2005) when called upon. Bode et al (2011) hinted that resource dependence between supply chain partners may affect the choices of mitigation strategies, while the antecedents and impacts of resource dependence between supply chain partners to response modes were not examined. 
There might be additional and more fundamental factors that constrain, or at least condition, the range of temporary sourcing diversification, for example, product design and production process. The design and nature of products for which the supply chain is created, such as product complexity, uniqueness (Lamming, 2000) and customization versus standardization (Asanum, 1988), are believed to have an impact on the production processes used and riskiness of the supply (Kleindorfer and Saad, 2005; Tomlin and Wang, 2010). In the supply disruption risk literature, recently, Ellis et al (2010) noted product attributes as one factor, among many environmental, organizational and individual factors, which can affect the firm's perceptions of supply chain disruption risks and the actions they take to mitigate supply disruption risks. The literature taken together seems to suggest that - the more specialized the item or the more specialized the activity, the fewer capable temporary providers there are likely to be.

However, this causality between product-process characteristics and post-disruption response modes has not been explicitly and empirically studied in the supply disruption risk literature. Specific knowledge regarding "what” product and process attribute and "how” it affects supply disruption response modes is still lacking. In the present paper, our comparison of two empirical cases will reveal such "what” and "how”.

\section{Research Method and Data Collection}

This paper uses the case study methodology to analyze and compare the details of two cases in various dimensions, i.e. "what”, in order to shed light on "how” product/process attributes affect supply disruption response modes. The case study method can provide a systematic means to examine interdependent events, actors and mechanisms, or the "what" and "how" issues, in their real-life contexts (Yin, 2009), and permits in-depth analysis of many details which is not possible with other methodologies (Sridharan et al, 2005). Recently, in the operations and supply chain management literature, case studies have been increasingly shown to be useful to derive meaningful and significant contributions to both practices and theory building (Barrat et al, 2011; Tracey and Neuhaus, 2013). 
Our aim is to reveal the effects of technical factors (product and process attributes), among many other factors in a very rich context, on a social phenomenon that is disruption response mode. But, the causation between the social phenomenon, i.e. supply disruption response, and the key aspect of the context, i.e. the physical nature of the product item whose supply is disrupted, is difficult to attribute without analyzing the fine details of the products, processes, supply chain strategies and all kinds of disruption response activities together. The context and phenomenon that we aim to analyze are too complex for other research methodologies, and can be best investigated with integrated evidence from different sources, such as document reviews, interviews and on-site observations, etc (Yin, 2009). Facing such a situation of inquiry, we adopt the case study methodology, collecting, integrating and analyzing data from public sources, interviews and on-site observations during site visits, and continual communications with the interviewees over time. In particular, our juxtaposition of the two cases (Aisin Seiki versus Riken) allowed for comparing disaster responses when supply chain strategies are nearly the same, and analyze the differences across a few economic and technological dimensions.

Our case data collection and analysis was carried out through three stages. In the first stage (from 2007 to 2010) we searched various public sources, including news articles, public reports, company press releases and data books regarding the two companies, to retrieve and review information particularly related to respective supply chain disruptions at Aisin Seiki due to a fire in 1997 and Riken due to an earthquake in 2007, the respective products (whose supplies were disrupted), and the recovery processes. At the time of starting our research, there was far more information and materials on the Aisin Seiki fire and how the supply chain of P-valves (i.e. proportioning valves for automotive brakes) recovered from the disaster (Kakihara and Sørensen, 2002; Nishiguchi and Beaudet, 1998; 2000; Sheffi, 2005; Watts, 2003) than those on how Riken's production of piston rings recovered after the disruption due to an earthquake in 2007. Our data search was weighed toward the Riken case as we sought to balance the information available to analyze and compare the two cases from various technical and social-economic aspects. In fact, this present study is the first to systematically document and analyze the Riken case in the academic literature. In general, our public data search and review in stage one allowed us to build a general understanding of these two companies’ products and supply chains operations and build the basic historical timelines of the specific disasters and recoveries. 
In the second stage, we conducted a total of five visits to these two companies from 2010 to 2013 for more nuanced data, as listed in the following:

- $\quad$ On March 23, 2010, the first and third authors of the present paper visited Riken in Kashiwazaki, Niigata Prefecture, Japan. The visit lasted a half-day with overview presentation, plant tour of piston ring manufacturing facility that was damaged by the earthquake in 2007, Q\&A sessions, in-person interviews and subsequent informal interactions. We interviewed the head of production administration, who was personally involved in the disaster recovery. The visit was primarily to learn about the products and operations of the company, and in particular the lessons learned from the Riken plant's recovery from the earthquake.

- On March 26, 2010, the first and third authors of the present paper visited Aisin Seiki in Kariya, Aichi Prefecture, Japan. The visit lasted a full day with overview presentation, plant tour of the rebuilt facility that has replaced the plant that was destroyed by the fire in 1997, Q\&A sessions, in-person interviews and many subsequent informal interactions. We interviewed the following five managers, some of whom had been directly involved with the fire recovery: the head of the corporate risk management office, the director of production administration, the vice director of the plant's supply and purchasing department, the head of the public relations department, and a public relations manager. The visit was primarily to learn about the products and operations of the company, and in particular the lessons learned from the recovery of the Kariya Plant from the fire in 1997.

- $\quad$ On February 21, 2011, the third author of the present paper visited Aisin Seiki again, as well as its affiliated automotive brake company ADVICS. The visit lasted a half-day, during which interviews were conducted with a manager in the corporate risk department, the head of the Kariya plant, a senior manager in the plant control department, a senior manager in the plant administration department, a senior purchasing manager, and a manager in the corporate administration department.

- $\quad$ On July 13, 2012, the third author of the present paper visited Riken Corporation again. He interviewed the following five people, four of whom had been personally involved in the disaster recovery in 2007: a plant manager, the head of the precision manufacturing 
department, the head of production administration, a senior engineer in the product development division, and the head of the quality assurance department.

- On March 18, 2013, a PhD student of the third author visited Aisin Seiki and ADVICS. This student had also participated in the previous two visits to Aisin Seiki. Interviews were held with the head of the Kariya plant, as well as managers of the plant control department, corporate administration department, and risk management department.

Before each field visit, we sent a set of open questions to the company to prepare discussions. Such questions broadly covered general issues of product features (specification, customization, standardization, etc), product development (time, cost, capability, etc) and production process (equipment, tooling, flexibility, etc), system integration (components and systems, etc), day-today operations (single versus multiple sourcing, etc), as well as the historical details regarding these two disasters, supply disruptions, and recoveries. These categories of inquiry constitute the codes of a framework for later cross-case analysis and comparison.

During each visit, we carefully documented our observations of products, machines and processes by taking pictures (at the allowed places) and making sketches and written descriptions of them, and taking notes when learning from the engineers and managers during presentations, interviews and informal interactions. After returning from each visit, the co-authors exchanged the notes and both quantitative and qualitative data collected from the sites, and systematically coded and discussed the data and findings. After each field visit, the third author of the present paper, who is based in Japan, has continued interactions via email and phone with our interviewees at Aisin Seiki and Riken, to the present.

The third stage primarily involved data analysis. Following Miles and Huberman (1994), we first integrated and analyzed the details within each of the two cases separately, and then compared them across two cases, following a consistent framework which covers the aspects of general supply chain strategies, day-to-day operational contexts, product features, product development and production methods, the characteristics of the disasters and disruptions, as well as response modes. During this process, we communicated our intermediate analysis, findings and reports (building on the direct and indirect data collected in first two stages) with our interviewees and 
executives at the two companies, and received feedback on the validity of our analysis. In particular, our explanation of the differences in disruption recovery modes of these two cases was confirmed by managers of both companies in this comparative study. Before the end of March 2013, the present draft of this paper had been reviewed for factual accuracy, commented on, corrected, and officially approved by both companies for publication.

As a result, the data collection process was not truly staged but rather iterative and integrative. Throughout the five-year period, we intertwined data collection through public sources and fieldwork and interviews, and also continued communications with our interviewees at the companies, as we gradually developed the present paper. In the following, we report our analysis based on the evidence collected through the continual efforts from 2007 to 2013, first within each case respectively in Section 4, and then across cases in Section 5.

\section{Within-case Analysis}

\subsection{Aisin Seiki and fire}

Aisin Seiki Co. Ltd and its affiliated companies are one of the largest auto parts supplier groups in the world and a leading supplier of brake systems. A P-valve is a machined casting into which are inserted a number of valves, springs, and seals, as shown in Fig. 1 . Its size is about $8 \times 4 \times 3$ centimeters, and according to Nishiguchi and Beaudet (1998) it is priced between US\$8 and US\$14. While a relatively uncomplicated part, it is critical to safety and must be custom designed for each vehicle type in which it is installed--even four-door and five-door variants of the same car model will likely need different P-valves. The machining process, disrupted by the fire, consists of drilling holes of different sizes and at different angles in different but similar castings, all in one plane, varying with the requirements of each car model.

(Fig. 1 about here)

Over many years, Aisin Seiki developed strong operational capabilities required to provide Toyota with the required number and type of P-valve from among a growing variety on a JIT basis. As Aisin Seiki developed this capability, Toyota increased the number of different varieties. Soon, Aisin Seiki was so good at accommodating Toyota’s variety demands, low 
inventories, and rapid response at low cost that it had won nearly all of Toyota's requirements for this part. To meet these needs, Aisin Seiki developed specialized equipment that could machine the castings in many varieties with almost transparent and fast changeover capability to match Toyota's mix of required types, low inventory, and short delivery cycles. It was this equipment that was destroyed in the fire on Feb 1, 1997. Unaffected were the supply of castings themselves, production of components assembled into the machined castings, and the assembly area itself.

As shown in Table 1, in 1996, about 89.9\% of Toyota's P-valve purchases in Japan came from Aisin Seiki. To pursue efficiency and scale economy, Aisin Seiki located all its P-valve manufacturing lines in Japan in a single building on a seven-building complex in Kariya, Japan, with a daily volume of 32,500 P-valves when the fire broke out in 1997. Table 1 summarizes the shipments between the major suppliers and customers in the automotive P-valve market in Japan in 1996.

(Table 1 about here)

At 4 AM on Saturday, February 1, 1997, a fire broke out that ignited several wooden platforms in building No.1 at the Kariya complex. It has been impossible to pinpoint the exact cause of the fire, but the current plant management holds that the most likely cause was an overheated generator that had been located on the shop floor. The building essentially burned down, and the special-purpose equipment for machining P-valve castings was destroyed. By 9 AM that day, Aisin’s production capacity for P-valves had vanished almost entirely. Toyota and Aisin Seiki only held two or three days of stock because of their dedication to JIT production principles. On Tuesday, February 4, Toyota was forced to shut down 20 of its 30 Japanese vehicle assembly lines because it had no more P-valves, and production ceased at all of its lines on Wednesday February 5. Consequently, several hundred suppliers to Toyota also had to stop production.

At that time, Toyota was producing about fifteen thousand cars per day in Japan, with an estimated value of around a quarter billion dollars. But it would take Aisin months to rebuild because of the requirement of procuring replacement machinery and creating a new production site. However, potentially enormous losses were largely averted by the immediate efforts of 
other suppliers, from both inside and outside the Toyota group, to recover the P-valve supplies. While the day-to-day relationship was single source and fortification, the response can be characterized as temporary sourcing diversification, or temporary multiple sourcing.

Aisin Seiki and Toyota immediately took measures to set up alternate production facilities of varying efficiency inside Aisin Seiki and its group companies that ultimately machined most of the P-valves, before full production on the original equipment was restored (See Fig. 2, from authors' fieldwork). At the same time and within just one day of the fire, other suppliers including those with little experience with P-valves responded to requests for help, obtained engineering drawings and technical information from Aisin Seiki, and set up alternative production sites and taskforces to machine the castings, which would be delivered to Aisin Seiki. After being inspected and approved by Aisin Seiki, the castings were assembled to the other components and sent to Toyota and other clients of Aisin Seiki. The first acceptable in-house Pvalves were available in very low quantities from February 5, and from collaborating suppliers beginning on February 7. Note that most of the P-valve castings were machined by Aisin Seiki after the first month using less efficient methods until the original machines were refurbished and returned to production. The temporary alternate suppliers never provided more than about $30 \%$ of Aisin Seiki’s needs.

(Fig. 2 about here)

More than 200 companies participated in the collaboration for impromptu supplies of machined castings, and approximately 62 of these firms directly produced P-valves. Such active collaborative efforts, including managing schedules and delivery priorities, were orchestrated by Aisin Seiki, with the participation but not the central control of Toyota. There were neither upfront negotiations on technical proprietary rights nor discussion of financial compensation, rather Aisin Seiki and Toyota either reimbursed the costs involved in the impromptu P-valve production and/or otherwise rewarded those suppliers who came to help (Nishiguchi and Beaudet, 1998). 
By Thursday, February 6, two of Toyota's assembly plants were reopened. On Monday, February 10, nine days after the fire started, all Toyota group plants were back to pre-disaster production volumes. In all, Toyota lost only four and a half days of production, despite Aisin Seiki's having lost at least five weeks of production. Total loses by Aisin Seiki and Toyota are estimated to have been several hundred million dollars. Without the cooperation of the suppliers, Toyota's losses would surely have been much higher.

Aisin Seiki's long-term response to this disaster was to rebuild the factory complex of seven buildings where the fire occurred, replacing them with one modern building extensively equipped to prevent fires from occurring or spreading. A fire remembrance day is held each year on February 1 and fire drills are frequent. In 2011, Aisin Seiki transferred this factory to ADVICS Co. Ltd, an affiliated company, to focus on other products. Today, many of the functions of the P-valve have been incorporated into other brake system components and, as of 2012, only about half as many P-valves are made each year as were made in 1997.

\subsection{Riken Corporation and earthquake}

Riken Corporation, the largest supplier of piston rings in Japan, supplies piston rings to all Japanese automobile manufacturers. A piston ring is a tiny working part in an internal combustion engine, as shown in Fig. 3. It requires special processes and tools to produce because its precision is essential to an engine's efficiency and durability. There are only three major automotive piston ring producers in Japan.

(Fig. 3 about here)

Riken has specialized in piston ring design and manufacturing technologies so that other suppliers have had difficulty emulating Riken. This situation also made it difficult for carmakers to diversify their piston ring purchasing sources in Japan (Nakamoto, 2007). As shown in Table 2, Riken held a 49.9\% share of the automotive engine piston ring market (by quantity) in Japan, and supplied to all twelve major Japanese automobile manufacturers, in 2005.

(Table 2 about here) 
While every reciprocating engine has piston rings and they look superficially alike to a lay person, in fact piston ring design and production are highly specialized and tailored to each target engine. It takes several years of design and testing to develop suitable piston rings for a given engine. Engine designers visit Riken frequently and interact deeply with the developers of "their" rings and the specific process equipment that will be used to make the rings for "their" engine.

On July 16, 2007 at 10:13 AM, a magnitude 6.6 shallow earthquake occurred near the west coast of Honshu, and was followed hours later by a magnitude 6.8 deep earthquake in Niigata, Japan. Riken's piston ring production facilities in Japan, located in the city of Kashiwazaki close to the epicenters of the earthquakes, were hard hit by the earthquake. Production of piston rings was disrupted for two weeks because of the significant damage to that plant's facilities and equipment, in particular the heavier ones. Fig. 4 shows the overturned machines and spilled inventory at Riken after the earthquake. This led to an estimated loss to the Japanese automotive industry of about 100 billion Japanese Yen, or about US\$820 million (Arup, 2007). Riken has stated that its own direct loss through equipment damage and lost inventory caused by the earthquake to be 1.5 billion yen.

(Figure 4 about here)

The larger industry losses reflect what was incurred by the downstream automakers and the many affected suppliers who were impacted by the consequent ripple effects through the automotive supply chains. In this case, the automakers held low inventories of piston rings, and were heavily dependent on Riken for piston ring supplies. Riken was the sole-source supplier of the piston rings for many car models of the automakers at the time of the earthquake (Nakamoto, 2007). With Riken shut down, automakers could not manufacture many engines and vehicles.

Toyota was forced to stop operations at all twelve of its domestic plants, and lost production of more than 120,000 cars (Global Risk Miyamoto, 2007). According to Honda (2007), seven plants, including three for automotive production, three for engine production and one for motorcycle production, were halted due to the piston ring production disruption at Riken. 
Immediately after the shutdown, the automakers provided various forms of assistance, including engineering and repair, to Riken. According to a Riken Corporation Press Release on July 19, three days after the earthquake, its customer companies including automakers as well as equipment manufacturers had sent approximately 650 people including many equipment engineers to help its recovery. The recovery was orchestrated by Toyota, which utilized experience it had gained from the Kobe earthquake of 1995 in order to decide what kind of help was needed in what sequence. Such management and collaboration helped Riken restart its production of piston rings much more quickly than it would have been able to on its own. Riken had its own disaster recovery plan but that proved immediately to be inadequate. Production resumed on July 23 (Riken Corporation Press Release, 2007), within a week of the earthquake, and fully recovered within two weeks (Global Risk Miyamoto, 2007). Fig. 5, based on information collected from our interviews, documents the milestones in the recovery process.

(Fig.5 about here)

After the disaster, Riken planned to spread out its production of piston rings to multiple locations in Japan and even abroad due to the effects of this earthquake (Global Risk Miyamoto, 2007). However, this diversification was not instituted. Instead, Riken reinforced its buildings, anchored down its production equipment and still today produces all of its piston rings for Japanese customers in Japan in the same buildings at and around the same site. However, as a buffer against any future severe disruptions, it has placed about a week of inventory nearer to its customers' factories. Riken still provides a large fraction of the Japanese car industry’s piston rings. It has also completely rewritten its disaster recovery manual.

\section{Cross-case analysis}

In the following, we compare these two cases in the same industry and cultural context, following a framework that covers the respective aspects of day-to-day strategies and operations, the characteristics of the disasters and disruptions, product features, product development and production methods, as well recovery/response modes. Table 3 summarizes the key similarities and differences in these aspects. 
(Table 3 about here)

Both cases involve severe disruption of an intentional single-sourcing arrangement in day-to-day operations. Both include evidence that the recovery was somewhat impromptu and began almost immediately, that some special techniques were involved in making the affected item, and that ingenuity was required to carry out the recovery. The major difference is that the Riken case requires a process that is impractical to duplicate within the time horizon needed, whereas in the Aisin Seiki case alternate suppliers and competitors volunteered or were willing and able to help when asked. The contrast of these two cases in disruption response modes offers an opportunity to reveal a "variable" of response mode, by tracing different responses to the differences in economic and technological fundamentals.

In both cases, the disrupted suppliers were the single source of the assembler, Toyota, for a specific automotive part used in its vehicles. The essential difference is that in principle almost any competent machine shop can, on short notice, machine the casting for a P-valve that will satisfy the needs of the car for which it is intended. The mere fact that dozens of companies, some from outside the automotive industry, could gear up so quickly is prima facie evidence that P-valve machining is really not very difficult to learn and do correctly, even though most of the responding companies had difficulties for the first day or two. Such difficulties are in fact not that unusual in typical production ramp-ups. However, it is not possible for anyone, even another piston ring manufacturer, to make, on short notice, a piston ring that will function properly with a given engine. Piston rings and engines are co-designed over a period of approximately 3 years (according to our interviewees) with constant and close coordination between their respective designers to develop the correct design and manufacturing technique, and to verify that the final output on the full-volume line precisely meets the design requirements.

A P-valve's manufacturing method and process are rather independent of a car, whereas the design of a P-valve is coupled to the design of a specific car. Coupling of car and P-valve gives rise to small differences in shape and interfaces that do not affect the manufacturing technique in principle. In relief from the fire in 1997, the substitute suppliers indeed did not use Aisin Seiki's machining methods or achieve its low costs, flexibility, and high volumes. But the machining required for P-valves is generic enough that alternate methods, with different capabilities for 
volume-variety combinations, can be learned very quickly (hours or days). In response to the disruption, many alternate suppliers were needed due to the huge volume and variety needed, and the relative inefficiency of the alternate methods the different suppliers had to use. No single alternate supplier necessarily had to, or perhaps even could, provide all the different types or the whole quantity needed of each type.

The unspecific nature of P-valve production methods/processes and the ease of substituting suppliers on short notice are atypical of manufactured parts. In automobiles, we can think of commodity fasteners as among the least specific parts used. Tires are often substitutable because their sizes and internal construction are somewhat standardized. But nearly everything else, from alternators and radiators to seats and dashboards, are designed specifically for a given car. Even if capable manufacturers exist for each of these kinds of items, the differences between parts that make them suitable for a given car require months or years to develop in each case. Temporary sourcing diversification for high-volume/high-variety parts on short notice after a disaster is likely to be only rarely possible.

Temporary sourcing diversification is impossible with a part like a piston ring. Piston rings are among the most specific parts in a car due to the tight coupling of their design and manufacturing method to their intended engine. This coupling makes it impractical not only to find substitute suppliers after a disruption but also to create multiple suppliers a priori by dividing the supply of piston rings for one engine among two or more suppliers because of the expense and time required to duplicate the lengthy design process and validation of correct manufacturing methods. This creates quite high asset specificity (Williamson, 1981; 1985), or resource dependence (Bode et al, 2011) between the supplier and assembler. High asset specificity makes it difficult to obtain or learn capabilities quickly when needed. The historical evolution of the piston ring industry in Japan further reduces the possibilities for temporary multiple sourcing, there being only three such companies.

Neither Aisin-Seiki nor Riken has changed its general supply chain strategy since these two respective disruptions. For normal day-to-day operations, Toyota, Aisin Seiki and Riken used fortification as the general sourcing strategy, and still do so after the respective disruption events. 
Toyota's supply chain maintains single-sourcing and long-term relationships with suppliers, and reaps both design synergies and operational benefits. ADVICS (Aisin Seiki's successor company for P-valve production) still supplies nearly all of Toyota's P-valves, and Riken has not built another piston ring plant in Japan. In our interviews, both companies cited the benefits of this apparently risky choice.

In the case of automotive piston rings for which specificity is the key to product and operational excellence, diversification may impose operational and organizational complexity and loss of value (quality, cost and delivery) achievable from concentration, and thus a disadvantage vis-àvis the competitors which adopt concentration for the item. The piston ring industry as a whole is highly concentrated in Japan (see Table 2). In fact, U.S. car manufacturers also adopt the single source strategy for the piston rings of a given engine even though there are more available U.S. suppliers.

In the case of P-valves, the relatively low asset specificity required for machining them and the successful temporary sourcing diversification in Aisin Seiki recovery may drive one to consider supply diversification for the item even during normal days, which can potentially mitigate the risk of supply disruption, reduce the cost of restoration and the loss in revenue. Simply put, for P-valves, supply diversification is a feasible choice but one not taken by Toyota for day-to-day operations. Why not?

Generally, fortified supply can reinforce the alignment of product design and manufacturing method, foster mutual learning about these alignments, and create scale economies. Specifically, in the case of Toyota's sourcing of P-valves, because Toyota cars use a huge variety of P-valves, the supplier that outperforms competitors must have effectively combined operational efficiency with flexibility. To address Toyota's variety needs, Aisin Seiki developed and applied flexible equipment with low or zero change over costs, with the ability to meet Toyota's JIT requirements. Despite being capable of making a P-valve, no other machine shop than Aisin Seiki could do this complex fulfillment when Toyota increased its variety of P-valves over time. This gave Aisin Seiki an unbeatable cost advantage over available competitors so it had by 1997 
won almost all of Toyota's business for P-valves in Japan. Aisin-Seiki indeed developed specific assets, as did Riken.

The difference is that the temporary alternate suppliers of P-valves did not need to duplicate Aisin-Seiki’s specific assets but could provide some of the required types and quantities of some P-valves using their own assets and methods. Because these alternate assets were relatively inefficient, many substitute suppliers were needed. The Kariya region of Japan, where Toyota and Aisin-Seiki are located, is rich in machine shops due to the nearby presence of Toyota, Mitsubishi Motors, and other major manufacturing companies, as well as the region's heritage as a center of aircraft production in past decades.

In summary, diversification is relatively easier to apply to assets that require less specific capabilities and are readily available from alternate sources. Aisin Seiki's P-valves fall into this category. Diversification is more difficult to apply to specialized assets or those with few alternate sources. Riken's piston rings fall into this category. However, Toyota used and still uses fortification rather than diversification for day-to-day supplies of both cases, with the belief that long-term benefits of learning, quality, efficiency and low cost from it far outweigh the risks of a rare disruption. Therefore, in the event of a disruption of a single sourcing supply chain (for long-term benefits), temporary sourcing diversification becomes extremely desirable when it works as evidenced in the Aisin Seiki recovery story. However, temporary sourcing diversification may not be possible when needed, for instance, when high degree of specificity is required in the development and production methods of the disrupted item.

\section{Discussion and theoretical contribution}

The forgoing analysis sheds light on the fact that, the more specialized the disrupted item and related design and product methods and assets are, the fewer capable temporary providers there are likely to be to provide temporary alternate supply. In the other words, temporary sourcing diversification is more feasible in the situations where the assets and capabilities required to develop and produce the disrupted physical item are less specific and are readily available from alternate sources. This is the main proposition from the present study, and focuses on the 
technical conditions on the feasibility of the temporary sourcing diversification mode of disruption response. In contrast, the past literature which advocates temporary sourcing diversification as highly desirable in the event of the disruption of single-sourcing supply chain (Nishiguchi and Beaudet, 1998; Sheffi, 2005; Watts, 2003) has largely overlooked the technical constraints to it.

In the literature, the feasibility of broad temporary diversification mode has been advocated and primarily attributed, as shown in the Aisin Seiki case, to the unique industrial culture and institutional mechanisms in Japan, such as Keiretsu, which foster trust, collaboration and capability sharing among firms, thus helps when needed in the event of disruption (Nishiguchi and Beaudet, 1998). However, the new Riken case, which shares the same Japanese context with the Aisin Seiki case (including Keiretsu-like relationships), exhibited a completely different disaster relief and disruption recovery mode for the reasons cited above. In addition, many of these praise-worthy characteristics deemed unique to Japan are also more widely distributed than may have been thought.

For instance, a fire in 2005 destroyed 80\% of the facilities of Rotoflex in Switzerland. ${ }^{1}$ Rotoflex is a small company that makes special dyes for coloring flexible food packaging film, using flammable volatile solvents. It was and is still the only Swiss supplier of this kind of dyes, implying its single-source relationships with customers. Three other companies agreed to start up production without any legal or financial agreements in place but later drove hard bargains. Among these alternate suppliers was one of its chemical suppliers who advanced credit for six months. Rotoflex's special equipment, tools, and production facilities were restored after six months. The temporary sourcing diversification mode of Rotoflex in Switzerland is not that different from the Aisin Seiki case in fundamental ways.

Meanwhile, a Riken-like response is more likely than the Aisin-Seiki response after severe supply disruptions, because so many components and parts in complex products require high degree of design specificity and highly specific assets to make them, in order for high quality and

\footnotetext{
${ }^{1}$ This short description was written based on the interviews with company representatives conducted by the authors' research collaborators based in Europe, as well as public data.
} 
lost cost driven by competition. Relatively few items in most competitive industries are generic enough in production methods/tools/equipment that temporary impromptu diversification will be possible. The high specificity of a disrupted item and the required high asset specificity in development and manufacturing methods and processes make it difficult to obtain or learn capabilities quickly when needed, thus constrain the range of responses to supply chain disruptions. Facing high product and asset specificity, intense concentrated recovery efforts may be the only practical disruption response strategy.

Yet we find that Toyota, as well as other lean manufacturers, persists in a fortified singlesourcing strategy for sourcing in day-to-day supply chain operations, because of the belief that long-term strategic benefits of fortification will outweigh the risks of disruption. The recent literature has also suggested single-sourcing and a fortification strategy are favorable from a long-term perspective (Chopra and Sodhi, 2014). However, the risks and losses from the disruption of such fortified single-sourcing supply chains might be underestimated, with the belief that temporary alternative supplies would be available impromptu when a disaster disrupts the single normal-day source (Nishiguchi and Beaudet, 1998; Sheffi, 2005; Watts, 2003), and without the awareness of the technical constraints to the desirable temporary sourcing diversification strategy, revealed in the present study.

Here, we show that the temporary diversification mode may not be feasible when the disrupted item has high specificity in product design and in the methods and assets required to develop and produce it. Clearly, the unawareness of the technical limits to temporary sourcing diversification or being overly optimistic about its availability may result in insufficient or inappropriate disaster preparedness in practice. If supply chain managers analyze product and production process characteristics and realize that temporary diversification may not be possible, they will develop more sophisticated mitigation initiatives and re-assess the required investments for a concentrated intense recovery, anticipating a disruption, as suggested by Zsidisin and Wagner (2010).

Taken together, this study has contributed to the broad literature on single versus multiple sourcing from a risk perspective (Costantino and Pellegrino, 2010; Trevelen and Schweikhart, 
1988; Wang, 2006; Wang and Tomlin, 2010), with a focus on supply disruption risks and responses (Bode et al, 2011; Ellis et al, 2011; Hoffmann et al, 2013; Kleindorfer and Van Wassenhove, 2004; Kleindorfer and Saad, 2005; Simchi-Levi et al, 2014) of single-sourcing supply chains (Nishiguchi and Beaudet, 1998; Sheffi, 2005). Specifically, we focus on the impact of products and processes attributes on supply disruption recoveries, a factor that had been under-investigated in the past literature (Ellis et al, 2010). Understanding the specific technical constraint is the first step toward developing nuanced initiatives to manage disruption risks in a context characterized by high specificity in products and processes, and also helps refine the general frameworks of supply disruption risk management (Kleindorfer and Saad, 2005).

\section{Limitations and future directions}

This study is still very limited. First of all, we only focused on one factor out of many hidden ones that may affect supply disruption response modes. For example, while different kinds of disasters may have different impacts on supply chains and firms (Altay and Ramirez, 2010), our two cases, in which the fire and earthquake were severe to equivalent degrees, do not support the study of disaster type/extent as a variable for response modes. Luck also played a large role in both cases. Had the fire occurred in the next-door building where Aisin Seiki made most of its brake master cylinders, the observed rapid response would have been even harder to achieve due to the more difficult manufacturing steps required for master cylinders. Similarly, had the earthquake measured 9 instead of 6.6, the damage to Riken's specialized machines might have been permanent rather than temporary, causing many months of disruption.

Second, our data and comparison primarily focused on Japan. We were aware of this limitation in our research, and in this paper have briefly compared the Japanese cases with a supply disruption case in Europe, in which the disruption response was not that different from the Japanese cases. Similarly, Revilla and Sáenz (2014)'s empirical analysis of 69 countries found no significant differences in disruption management practices across countries, despite differences in risk sources. We speculate that our findings should also be applicable widely across countries, pending rigorous tests based on data from many countries. 
Future studies of a larger sample of cases and scenarios may allow additional factors to be revealed in depth. The current study is constrained by the data available. Even for the focus on one factor (product and asset specificity), the usefulness of case studies is largely limited to the exploratory stage. To advance further, survey data for systematically defined variables and statistical analysis are required to test our proposition and deepen preliminary understandings. In addition, in cases characterized by high product and asset specificity, intense concentrated recovery efforts seem to be the only practical response mode. We expect more research to identify novel strategies and develop systemic management initiatives that offer alternative response strategies. There remain many opportunities for research to understand and manage supply disruption risks, as pointed out by Schoenherr et al (2012).

\section{References}

Allbusiness, 2007. Despite Riken rings shortage, Japan's auto-industry managers cling to JIT. August 10, 2007. http://www.allbusiness.com/manufacturing/transportation-equipmentmfg-automotive/5514121-1.html. Retrieved on March 29, 2009.

Altay, N., Ramirez, A., 2010. Impact of disasters on firms in different sectors: implications for supply chains. Journal of Supply Chain Management, 46 (4), 59-80.

Arup N.A., 2007. An Arup Reconnaissance Report - The July 16, 2007 Niigata Chuetsu-oki Japan Earthquake, San Francisco, California.

Asanuma, B., 1989. Manufacturer-supplier relationships in Japan and the concept of relationspecific skill. Journal of the Japanese and International Economies, 3(1), 1-30.

Baldwin, C.Y., Clark, K.B., 2000. Design Rules, Volume 1: The Power of Modularity. MIT Press, Cambridge, MA.

Barratt, M., Choi, T.Y., Li, M., 2011. Qualitative case studies in operations management: Trends, research outcomes, and future research implications. Journal of Operations Management, 29(4), 329-342.

Bode, C., Wagner, S.M., Petersen, K.J., Ellram, L.M., 2011. Understanding responses to supply chain disruptions: insights from information processing and resource dependence perspectives. Academy of Management Journal, 54 (4), 833-856.

Braunscheidel, M.J., Suresh, N.C., 2009. The organizational antecedents of a firm's supply chain agility for risk mitigation and response, Journal of Operations Management, 27 (2), 119140.

Chopra, S., Reinhardt, G., Mohan, U., 2007. The importance of decoupling recurrent and 
disruption risks in a supply chain. Naval Research Logistics, 54 (5), 544-555.

Chopra, S., Sodhi, M.S., 2014. Reducing the risk of supply chain disruptions. MIT Sloan Management Review, 55 (3), 72-73.

Chozik, A., 2007a. A key strategy of Japan's car makers backfires. Wall Street Journal, July 24, 2007.

Chozik, A., 2007b. Toyota sticks by “Just in Time” strategy after quake. Wall Street Journal, July 24, 2007.

Costantino, N., Pellegrino, R., 2010. Choosing between single and multiple sourcing based on supplier default risk: a real options approach. Journal of Purchasing \& Supply Management, 16 (1), 27-40.

Courtland, R., 2011. How Japanese chipmaker Renesas recovered from the earthquake. IEEE Spectrum, August. http://spectrum.ieee.org/semiconductors/processors/how-japanesechipmaker-renesas-recovered-from-the-earthquake. Retrieved on December 21, 2011

Dada, M., Petruzzi, N.C., Schwarz, L.B., 2007. A news-vendor's procurement problem when suppliers are unreliable. Manufacturing \& Service Operations Management, 9(1), 9-32.

DeHoratius, N., Rabinovich, E., 2011. Field research in operations and supply chain management. Journal of Operations Management, 29(5), 371-375.

Ellis, S.C., Shockley, J., Henry, R.M., 2011. Making sense of supply disruption risk research: a conceptual framework grounded in enactment theory. Journal of Supply Chain Management, 47 (2), 65-96.

Fine, C.H., Whitney, D.E., 1999. Is the make-buy decision a core competence? In: Muffatto, M., Pawar, K. (Eds.), Logistics in the Information Age. Servizi Grafici Editoriali, Padova, Italy, pp. 31-63.

Fujimoto, T., 2001. The Japanese automobile parts supplier system: The triplet of effective interfirm routines. International Journal of Automotive Technology and Management, 1(1), 134.

Fujimoto, T., 2007. Competing to Be Really, Really Good: The Behind-the-Scenes Drama of Capability-Building Competition in the Automobile Industry. I-House Press, Tokyo.

Giannakis, M., Louis, M., 2011. A multi-agent based framework for supply chain risk management. Journal of Purchasing \& Supply Management, 17 (1), 23-31.

Global Risk Miyamoto, 2007. 2007 Niigata Chuetsu-Oki Japan Earthquake Reconnaissance Report. Sacramento, California.

Griffy-Brown, C., 2003. Just-in-time to just-in-case. Graziadio Bus. Rep. 6.

Hoffmann, P., Schiele, H., Krabbendam, K., 2013. Uncertainty, supply risk management and their impact on performance. Journal of Purchasing \& Supply Management, 19 (3), 199211. 
Honda, 2007. Update on Earthquake Impact to Honda’s Production Activity, on July 20, 23, 24, 25, 2007, Honda News Archive, http://world.honda.com/news/2007/

Hopp, W.J., Spearman, M.L., 2004. To pull or not to pull: What is the question? Manufacturing \& Service Operations Management, 6(2), 133-148.

IRC, 1999. Report on Production and Transactions of 200 Auto Components, Industry Research and Consulting (IRC), Tokyo, Japan.

IRC, 2008. Report on Production and Transactions of 200 Auto Components, Industry Research and Consulting (IRC), Tokyo, Japan.

Kakihara, M., Sørensen, C., 2002. Exploring knowledge emergence: From chaos to organizational knowledge. Journal of Global Information Technology Management, 5(3), 48-66.

Kleindorfer, P.R., Saad, G.H., 2005. Managing disruption risks in supply chains. Production \& Operations Management, 14(1), 53-68.

Kleindorfer, P.R., Van Wassenhove, L.N., 2004. Managing risk in the global supply chain. In: Gatignon, H., Kimberley, J.R. (Eds.), Strategies for Building Successful Global Businesses. Cambridge University Press, Cambridge, MA, pp. 288-305.

Knemeyer, A.M., Zinn, W., Eroglu, C., 2009. Proactive planning for catastrophic events in supply chains. Journal of Operations Management, 27(2), 141-153.

Lamming, R., Johnsen, T., Zheng, J., Harland, C., 2000. An initial classification of supply networks. International Journal of Operations \& Production Management, 20(6), 675-691.

Liker, J.K., Choi, T.Y., 2004. Building deep supplier relationships. Harvard Business Review, 82(12), 104-113.

Luo, J., Baldwin, C.Y., Whitney, D.E., Magee, C.L., 2012. The architecture of transaction networks: a comparative analysis of hierarchy in two sectors, Industrial and Corporate Change, 21(6), 1307-1335.

MacDuffie, J.P., 1995. Human resource bundles and manufacturing performance: Organizational logic and flexible production systems in the world auto industry. Industrial and labor Relations Review, 48(2), 197-221.

MacDuffie, J.P., 2008. Technological and organizational barriers to modularity: Persistent integrality in the global automotive industry. International Motor Vehicle Program Working Paper, Version 1.5, January 10, 2008.

Miles, M. B., Huberman, A. M., 1994. Qualitative Data Analysis: An Expanded Sourcebook. SAGE

Nakamoto, M., 2007. Quake upsets lean supply model, Financial Times, July 23, 2007.

Narasimhan, R., Talluri, S., 2009. Perspectives on risk management in supply chains. Journal of Operations Management, 27(2), 114-118. 
Nishiguchi, T., Beaudet. A., 1998. The Toyota group and the Aisin fire. MIT Sloan Management Review, 40(1), 49-59.

Nishiguchi, T., Beaudet, A., 2000. Fractal design: self-organizing links in supply chain management. In: Von Krogh, G., Nonaka, I., Nishiguchi, T. (Eds.), Knowledge Creation: A Source of Value. Macmillan Press, London, pp.199-230.

Reitman, V., 1997a. Toyota’s factories in Japan grind to a halt. Wall Street Journal, Feb 4, 1997.

Reitman, V., 1997b. To the rescue: Toyota's fast rebound after fire at supplier shows why it is tough. Wall Street Journal, May 8, 1997.

Revilla, E., Sáenz, M.J., 2014. Supply chain disruption management: global convergence vs national specificity. Journal of Business Research, 67 (6), 1123-1135.

Riken Corporation Press Release, 2007. The Status of Recovery from the Damage of NiigataChuetsuoki Earthquake on Riken’s Kashiwazaki Plant (as of July 19), July 19, 2007.

Riken Corporation Press Release, 2007. Notice of the Resumption of Production at Riken Kashiwazaki Plant after the Niigata-Chuetsuoki Earthquake, July 23, 2007.

Riken Corporation Press Release, 2007. Apologies and Gratitude Regarding the Damage Caused by Niigata-Chuetsuoki, August 2, 2007.

Sako, M., 1992. Prices, quality, and trust: inter-firm relations in Britain and Japan. Cambridge University Press, Cambridge, UK.

Schoenherr, T., Modi, S.B., Benton, W.C., Carter, C.R., Choi, T.Y., Larson, P.D., Leenders, M.R., Mabert, V.A., Narasimhan, R., Wagner, S.M., 2012. Research opportunities in purchasing and supply management. International Journal of Production Research, 50(16), 4556-4579.

Sheffi, Y., 2007. The Resilient Enterprise: Overcoming Vulnerability for Competitive Advantage, MIT Press.

Simchi-Levi, D., Schmidt, W., Wei, Y., 2014. From superstorms to factory fires. Harvard Business Review 92, (1/2), 96-101.

Song, J.-S., Zipkin, P.H., 1996. Inventory control with information about supply conditions. Management Science, 42(10), 1409-1419.

Speier, C., Whippleb, J.M., Clossc, D.J., Voss, M.D., 2011. Global supply chain design considerations: Mitigating product safety and security risks. Journal of Operations Management, 29(7), 721-736.

Sridharan, U.V., Caines, W.R., and Patterson, C.C., 2005. Implementation of supply chain management and its impact on the value of firms. Supply Chain Management: An International Journal, 10(4), 313-318.

Tomlin, B., 2006. On the value of mitigation and contingency strategies for managing supplychain disruption risks. Management Science, 52(5), 639-657. 
Tomlin, B., 2009. Disruption-management strategies for short life-cycle products. Naval Research Logistics, 56(4), 318-347.

Tomlin, B., Wang, Y., 2005. On the value of mix flexibility and dual sourcing in unreliable newsvendor networks. Manufacturing \& Service Operations Management, 7(1), 37-57.

Tomlin, B., Wang, Y., 2010. Operational strategies for managing supply chain disruption risk. In: Kouvelis, P., Dong, L., Boyabatli, O., Li, R. (Eds.), Handbook Of Integrated Risk Management In Global Supply Chains. John Wiley and Sons, New York, pp. 79-101.

Tracey, M. and Neuhaus, R., 2013. Purchasing's role in global new product-process development projects. Journal of Purchasing \& Supply Management, 19(2), 98-105.

Treece, J. B., 1997. Just-too-much single sourcing spurs Toyota purchasing review. Automotive News, March 3.

Trevelen, M., Schweikhart, S.B., 1988. A risk/benefit analysis of sourcing strategies: single vs. multiple sourcing. Journal of Operations Management, 7 (4), 93-114.

Wagner, S.M., Silveira-Camargos, V., 2012. Managing risks in just-in-sequence supply networks: exploratory evidence from automakers. IEEE Transactions on Engineering Management, 59 (1), 52-64.

Wang, Y. Gilland, W.G., Tomlin, B., 2010. Mitigating supply risk: dual sourcing or process improvement? Manufacturing \& Service Operations Management, 12(3), 489-510.

Watts, D. J., 2003. Six Degrees: The Science of a Connected Age, Norton.

Whitney, D.E., 1993. Nippondenso Co. Ltd: A case study of strategic product design. Research in Engineering Design, 5(1), 1-20.

Williamson, O.E., 1981. The economies of organization: the transaction cost approach. American Journal of Sociology, 87(3), 548-577.

Williamson, O.E., 1985. The Economic Institutions of Capitalism: Firms, Markets, Relational Contracting. Free Press, New York.

Womack, J.P., Jones, D.T., Roos, D., 1990. The Machine That Changed The World: The Story Of Lean Production. Rawson Associates, New York, NY.

Yin, R.K., 2009. Case Study Research: Design and Methods, 4th ed. Thousand Oaks, CA: Sage Publications.

Zsidisin, G.A., Wagner, S.M., 2010. Do perceptions become reality? The moderating Role of supply risk resiliency on disruption occurrence. Journal of Business Logistics, 31 (2), 1-20. 
Table 1 Monthly supplies and purchases of proportioning valves (P-valves) in Japan, in 1996

\begin{tabular}{|c|c|c|c|c|c|}
\hline P-valve Supplier & $\begin{array}{c}\text { Total Production } \\
\text { (1,000 units / Month) }\end{array}$ & $\begin{array}{l}\text { Market } \\
\text { Share }\end{array}$ & Manufacturer & $\begin{array}{c}\text { Purchases } \\
\text { (1,000 units / Month) }\end{array}$ & Percentage \\
\hline \multirow[t]{6}{*}{ Aisin Seiki } & \multirow[t]{6}{*}{365.7} & \multirow[t]{6}{*}{$41.9 \%$} & Toyota Motor & 237 & $64.8 \%$ \\
\hline & & & Mitsubishi Motor & 76 & $20.8 \%$ \\
\hline & & & Isuzu Motor & 22.5 & $6.2 \%$ \\
\hline & & & Suzuki Motor & 21 & $5.7 \%$ \\
\hline & & & Daihatsu Motor & 9.2 & $2.5 \%$ \\
\hline & & & Nissan Motor & 0.01 & $0.0 \%$ \\
\hline \multirow[t]{4}{*}{ Nissin Kogyo } & \multirow[t]{4}{*}{162.8} & \multirow[t]{4}{*}{$18.7 \%$} & Honda Motor & 104.9 & $64.4 \%$ \\
\hline & & & Toyota Motor & 27 & $16.6 \%$ \\
\hline & & & Daihatsu Motor & 25.9 & $15.9 \%$ \\
\hline & & & Suzuki Motor & 5 & $3.1 \%$ \\
\hline \multirow[t]{3}{*}{ Nabco } & \multirow[t]{3}{*}{126.4} & \multirow[t]{3}{*}{$14.5 \%$} & Nissan Motor & 55 & $43.5 \%$ \\
\hline & & & Fujitsu Heavy Industry & 39.9 & $31.6 \%$ \\
\hline & & & Suzuki Motor & 31.5 & $24.9 \%$ \\
\hline \multirow[t]{2}{*}{ Tokico } & \multirow[t]{2}{*}{88.65} & \multirow[t]{2}{*}{$10.2 \%$} & Nissan Motor & 62.45 & $70.4 \%$ \\
\hline & & & Mazda Motor & 26.2 & $29.6 \%$ \\
\hline \multirow[t]{3}{*}{ Shinei Kogyo } & \multirow[t]{3}{*}{47} & \multirow[t]{3}{*}{$5.4 \%$} & Mazda Motor & 39 & $83.0 \%$ \\
\hline & & & Nissan Motor & 6 & $12.8 \%$ \\
\hline & & & Suzuki Motor & 2 & $4.3 \%$ \\
\hline \multirow[t]{6}{*}{ Bosch Japan } & \multirow[t]{6}{*}{42.99} & \multirow[t]{6}{*}{$4.9 \%$} & Mitsubishi Motor & 19.6 & $45.6 \%$ \\
\hline & & & Suzuki Motor & 15.5 & $36.1 \%$ \\
\hline & & & Nissan Motor & 6.54 & $15.2 \%$ \\
\hline & & & Honda Motor & 0.6 & $1.4 \%$ \\
\hline & & & Nissan Diesel & 0.5 & $1.2 \%$ \\
\hline & & & Isuzu Motor & 0.25 & $0.6 \%$ \\
\hline \multirow{4}{*}{$\begin{array}{l}\text { Sumitomo } \\
\text { Electric }\end{array}$} & \multirow[t]{4}{*}{33.15} & \multirow[t]{4}{*}{$3.8 \%$} & Daihatsu Motor & 25.9 & $78.1 \%$ \\
\hline & & & Mazda Motor & 3.8 & $11.5 \%$ \\
\hline & & & Isuzu Motor & 2.25 & $6.8 \%$ \\
\hline & & & Mitsubishi Motor & 1.2 & $3.6 \%$ \\
\hline \multirow[t]{4}{*}{ Akebono Brake } & \multirow[t]{4}{*}{5.3} & \multirow[t]{4}{*}{$0.6 \%$} & Hino Motor & 2.4 & $45.3 \%$ \\
\hline & & & Nissan Diesel & 1.6 & $30.2 \%$ \\
\hline & & & Fujitsu Heavy Industry & 1.1 & $20.8 \%$ \\
\hline & & & Mitsubishi Motor & 0.2 & $3.8 \%$ \\
\hline
\end{tabular}

Source: IRC, 1999 
Table 2 Monthly supplies and purchases of piston rings in Japan, in 2005

\begin{tabular}{|c|c|c|c|c|c|}
\hline $\begin{array}{l}\text { Piston Ring } \\
\text { Supplier }\end{array}$ & $\begin{array}{l}\text { Total Production } \\
\text { (1,000 units / Month) }\end{array}$ & $\begin{array}{c}\text { Market } \\
\text { Share }\end{array}$ & Manufacturer & $\begin{array}{c}\text { Purchases } \\
\text { (1,000 units / Month) }\end{array}$ & Percentage \\
\hline \multirow{12}{*}{$\begin{array}{l}\text { Riken } \\
\text { Corporation }\end{array}$} & \multirow[t]{12}{*}{485.2} & \multirow[t]{12}{*}{$49.9 \%$} & Honda Motor & 93.3 & $19.2 \%$ \\
\hline & & & Toyota Motor & 81.2 & $16.7 \%$ \\
\hline & & & Suzuki Motor & 76.1 & $15.7 \%$ \\
\hline & & & Mazda Motor & 71.4 & $14.7 \%$ \\
\hline & & & Nissan Motor & 69.2 & $14.3 \%$ \\
\hline & & & Fujitsu Heavy Industry & 29.2 & $6.0 \%$ \\
\hline & & & Mitsubishi Motor & 23.9 & $4.9 \%$ \\
\hline & & & Daihatsu Motor & 18.8 & $3.9 \%$ \\
\hline & & & Nissan Diesel & 10.9 & $2.2 \%$ \\
\hline & & & Mitsubishi Fuso & 9.4 & $1.9 \%$ \\
\hline & & & Isuzu Motor & 1.0 & $0.2 \%$ \\
\hline & & & Hino Motor & 0.9 & $0.2 \%$ \\
\hline \multirow{10}{*}{$\begin{array}{l}\text { Teikoku Piston } \\
\text { Ring }\end{array}$} & \multirow[t]{10}{*}{294.3} & \multirow[t]{10}{*}{$30.2 \%$} & Toyota Motor & 141.3 & $48.0 \%$ \\
\hline & & & Daihatsu Motor & 59.3 & $20.1 \%$ \\
\hline & & & Mitsubishi Motor & 41.6 & $14.1 \%$ \\
\hline & & & Suzuki Motor & 21.3 & $7.2 \%$ \\
\hline & & & Honda Motor & 16.5 & $5.6 \%$ \\
\hline & & & Isuzu Motor & 6.5 & $2.2 \%$ \\
\hline & & & Nissan Motor & 3.0 & $1.0 \%$ \\
\hline & & & Hino Motor & 2.4 & $0.8 \%$ \\
\hline & & & Mitsubishi Fuso & 2.3 & $0.8 \%$ \\
\hline & & & Nissan Diesel & small quantity & $0.0 \%$ \\
\hline \multirow{11}{*}{$\begin{array}{l}\text { Nippon Piston } \\
\text { Ring }\end{array}$} & \multirow[t]{11}{*}{193.6} & \multirow[t]{11}{*}{$19.9 \%$} & Toyota Motor & 78.2 & $40.4 \%$ \\
\hline & & & Nissan Motor & 31.0 & $16.0 \%$ \\
\hline & & & Daihatsu Motor & 26.1 & $13.5 \%$ \\
\hline & & & Mazda Motor & 17.8 & $9.2 \%$ \\
\hline & & & Isuzu Motor & 12.7 & $6.6 \%$ \\
\hline & & & Fujitsu Heavy Industry & 10.2 & $5.3 \%$ \\
\hline & & & Hino Motor & 9.8 & $5.1 \%$ \\
\hline & & & Suzuki Motor & 4.1 & $2.1 \%$ \\
\hline & & & Mitsubishi Motor & 2.7 & $1.4 \%$ \\
\hline & & & Nissan Diesel & 0.5 & $0.3 \%$ \\
\hline & & & Mitsubishi Fuso & 0.5 & $0.3 \%$ \\
\hline
\end{tabular}

Source: IRC, 2008 
Table 3 Summary of the comparison of the Aisin Seiki and Riken supply disruption and recovery cases

\begin{tabular}{|c|c|c|c|}
\hline & & Case 1 & Case 2 \\
\hline \multirow{5}{*}{$\begin{array}{l}\text { Disruption } \\
\text { Background }\end{array}$} & Supplier & Aisin-Seiki, Japan & Riken, Japan \\
\hline & Customer & Toyota, Japan & Toyota, Japan \\
\hline & Time & 1997 & 2007 \\
\hline & Disruption & Fire burned special machine system & Earthquake knocked over machines \\
\hline & $\begin{array}{l}\text { Pre-disruption sourcing } \\
\text { strategy }\end{array}$ & $\begin{array}{l}\text { Single sourcing and fortified } \\
\text { supplier-customer relationship }\end{array}$ & $\begin{array}{l}\text { Single sourcing and fortified } \\
\text { supplier-customer relationship }\end{array}$ \\
\hline \multirow[t]{3}{*}{ Product } & Item(s) disrupted & Brake proportioning valves & Piston rings \\
\hline & Importance of item(s) & $\begin{array}{l}\text { Needed for nearly all Toyota's cars } \\
\text { assembled in Japan }\end{array}$ & $\begin{array}{l}\text { Needed for half of Japanese car } \\
\text { industry }\end{array}$ \\
\hline & Product specificity & $\begin{array}{l}\text { Designed for each car, dozens of } \\
\text { types, complex fulfillment on JIT } \\
\text { basis }\end{array}$ & $\begin{array}{l}3 \text { year design and process } \\
\text { development needed to match ring } \\
\text { to engine }\end{array}$ \\
\hline \multirow[t]{2}{*}{ Process } & Processes disrupted & Machining of valve castings & $\begin{array}{l}\text { Specialized machining, heat } \\
\text { treating and finishing }\end{array}$ \\
\hline & Process specificity & $\begin{array}{l}\text { General machining - many shops } \\
\text { capable of the necessary machining }\end{array}$ & $\begin{array}{l}\text { Tailored to piston ring processes - } \\
\text { only another piston ring } \\
\text { manufacturer could do it }\end{array}$ \\
\hline \multirow[t]{4}{*}{$\begin{array}{l}\text { Response } \\
\text { Mode }\end{array}$} & What was done & $\begin{array}{l}\text { Dozens of competitors and other } \\
\text { shops machined them using their } \\
\text { own processes; no single shop could } \\
\text { machine all the different types or } \\
\text { meet the huge demand, i.e. } \\
\text { temporary sourcing diversification }\end{array}$ & $\begin{array}{l}\text { Riken machines were put back in } \\
\text { place (no spare industry capacity } \\
\text { and no time existed for } 3 \text { years of } \\
\text { development); Toyota organized } \\
\text { the recovery but Riken managed } \\
\text { the schedules and resolved priority } \\
\text { conflicts among its customers }\end{array}$ \\
\hline & $\begin{array}{l}\text { How long did the disruption } \\
\text { last }\end{array}$ & 3 months & $\begin{array}{l}1 \text { month with schedule disruptions } \\
\text { for several months }\end{array}$ \\
\hline & $\begin{array}{l}\text { How quickly did substitute or } \\
\text { recovered operations start }\end{array}$ & 4 days & 6 days \\
\hline & Additional information & $\begin{array}{l}\text { No discussion of payment until after } \\
\text { recovery }\end{array}$ & \\
\hline Afterwards & Sourcing Strategy & $\begin{array}{l}\text { Toyota continues single source } \\
\text { procurement of these parts }\end{array}$ & $\begin{array}{l}\text { Toyota continues single source } \\
\text { procurement of these parts }\end{array}$ \\
\hline
\end{tabular}
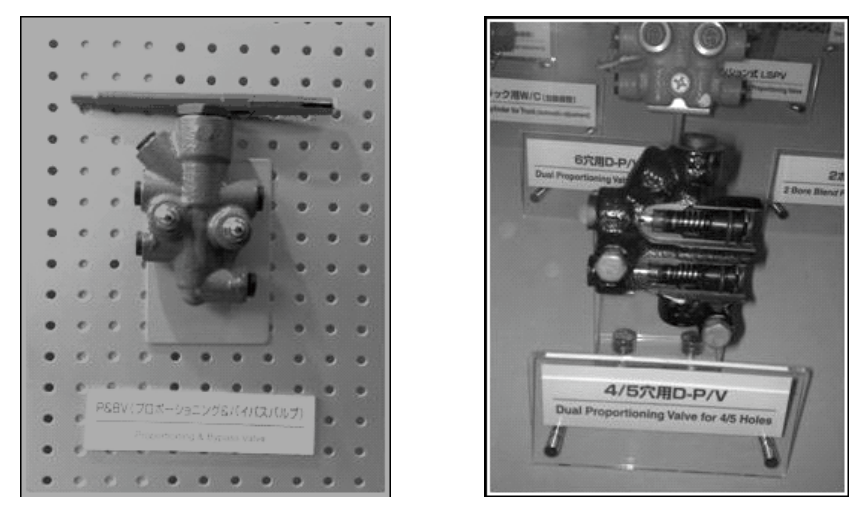

Fig. 1. A typical P-valve. Left: size comparison to a pen. Right: cutaway view.

(Source: photographed during the authors' visit to Aisin Seiki in 2010). Note the style differences between these two examples in terms of number and orientation of pipe connections. 


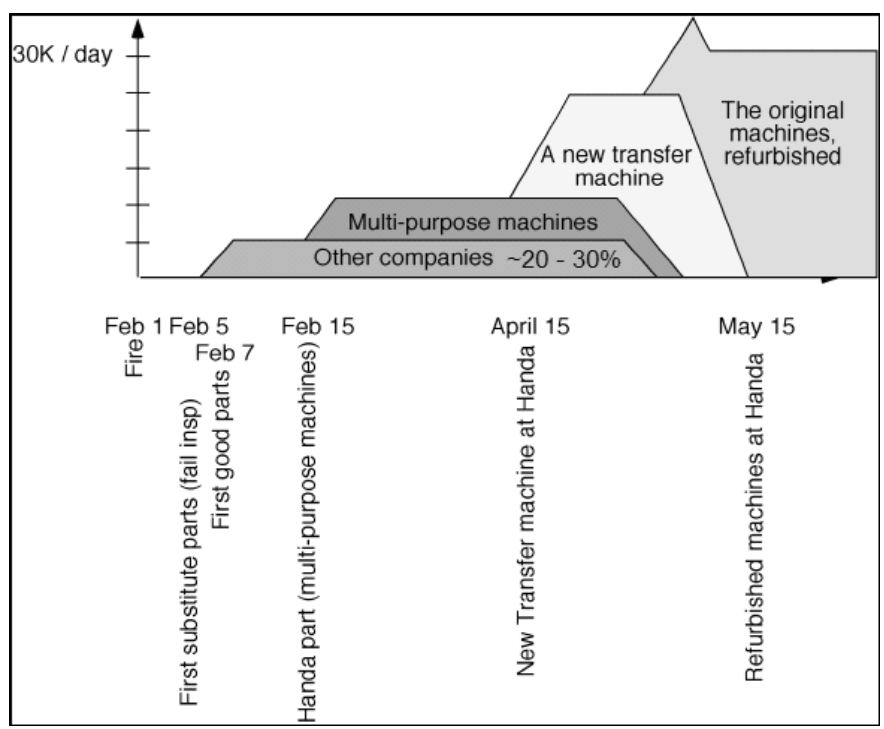

Fig. 2. Timeline of Aisin Seiki recovery.

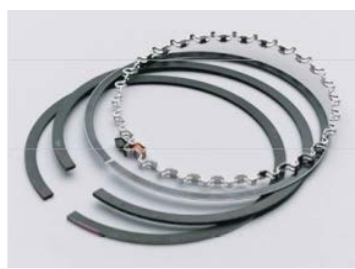

Fig. 3. Typical piston rings. Each piston usually has three rings, each of a different design and purpose. (Source: Riken Corporation) 

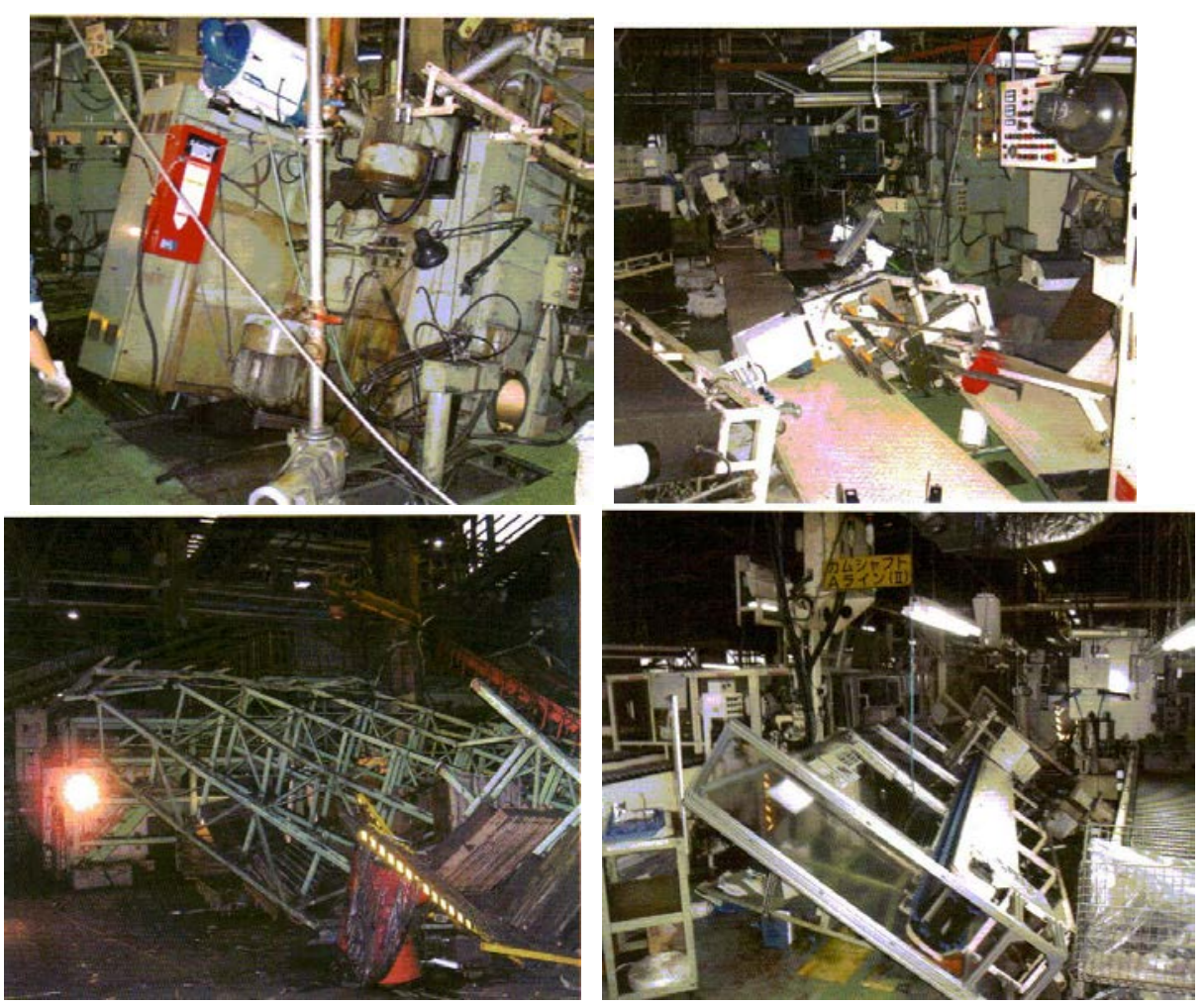

Fig. 4. Damage at Riken (Source: Riken Corporation)

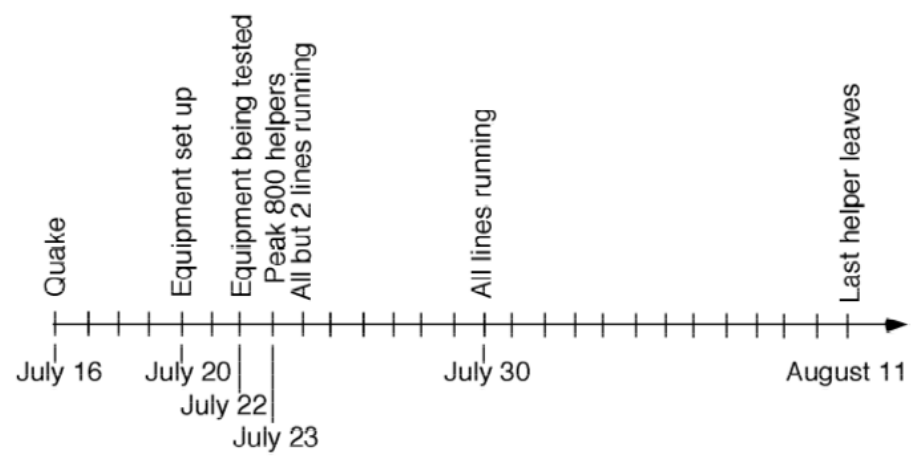

Fig. 5. Timeline of Riken recovery 